Research Article

\title{
Optimizing Parameters for Anticollision Systems between Adjacent Buildings under Earthquakes
}

\author{
Nan Jin (iD) and Yong-qiang Yang (iD) \\ Key Laboratory of Earthquake Engineering and Engineering Vibration, Institute of Engineering Mechanics, CEA, \\ 150080 Harbin, China \\ Correspondence should be addressed to Yong-qiang Yang; yangiem@foxmail.com
}

Received 19 May 2018; Revised 28 August 2018; Accepted 2 September 2018; Published 2 October 2018

Academic Editor: Chao Tao

Copyright (C) 2018 Nan Jin and Yong-qiang Yang. This is an open access article distributed under the Creative Commons Attribution License, which permits unrestricted use, distribution, and reproduction in any medium, provided the original work is properly cited.

\begin{abstract}
Adjacent buildings with anticollision system would have the possibility of pounding under earthquake if there is insufficient separate distance between the two buildings. The effect of pounding and earthquake characters on the optimum parameters for anticollision system is studied through time-history analysis method in this paper. Interstory displacement ratio, energy consumption ratio, and the total strain energy of the two buildings are considered as control variables. The results show that the pounding between adjacent buildings will reduce the range of optimum parameters, and earthquake characters also have effect on the selection of optimum parameters. Therefore, it is strongly recommended to input more than three ground motion records for a time-history analysis to get the optimum parameters considering the effect of pounding and earthquake characters.
\end{abstract}

\section{Introduction}

Investigations into past several strong earthquakes occurred in China showed that the failure of engineering structures was the main reason of the heavy losses in the earthquakes. Pounding between adjacent buildings or neighbor parts of the same building during the earthquakes is one of the most typical seismic damages. This pounding has often been recorded as an important cause of severe structural damage or even collapse in the earthquakes [1]. Pounding between neighbor buildings will occur if there is insufficient distance between the two buildings during the earthquakes. Although the seismic resistant design codes of most countries have specified the minimum distances between adjacent buildings, pounding still frequently occurs due to the failure of the implementing the specification strictly or the insufficient distance specified in the codes [2]. Those buildings with insufficient distances have high probability to suffer the severe damage due to the pounding. To avoid such undesirable consequence, it is necessary to propose effective mitigation measures to reduce the damage [3].
Several mitigation measures have been proposed to avoid the pounding between adjacent buildings, which can be classified into two main types $[4,5]$ : (1) filling with impact absorbing materials and (2) installing energy dissipation devices. For the absorbing materials, Miller [6] found the resonance interaction of the two structures without damping was significantly reduced if the pounding is inelastic during the earthquake. Anagnostopoulos [7] suggested to set the stiffness of pounding elements with a hundredth of real pounding stiffness, so that the displacement amplification of adjacent structures could be controlled efficiently. Rubber shock absorbers, as soft material layers, have been always investigated to install at certain locations of adjacent buildings, where poundings are expected, hence acts as collision shock absorbers in order to prevent the sudden impact pulse [8-11]. On the other hand, some researchers analyzed the performance of adjacent buildings connecting with fiction dampers and dampers based on Kelvin model and Maxwell model, giving out the optimum parameters of each damper through numerical simulation methods [12-20]. Bigdeli et al. [21] also studied on the configuration of the damper locations. Besides, Vincent et al. [22] present the results of large-scale 
shake table tests of two adjacent two-story structures subject to pounding, and the results can provide reference for the anticollision research of adjacent structures.

However, in previous studies regarding the mitigation measures with energy dissipation devices, the pounding between adjacent buildings is considered fully avoided, which is not exactly accordant to the real situation. In fact, the distances between great numbers of existing adjacent buildings are not large enough to avoid pounding completely. There are also some buildings which are not suitable for a large separate distance or seismic joint due to the requirement of architecture design. Pounding will still occur in these adjacent buildings, even though the energy dissipation devices are installed between them, which will induce severe damage during the strong ground motion excitation. Therefore, it is important to investigate adjacent buildings connected with anticollision system with the possibility of pounding. To this end, this paper (i) designs an anticollision system installing between two adjacent structures, (ii) defines three control variables as the criteria and proposes the method to select the optimum parameters of the anticollision system, (iii) compares the optimum parameters considering and without considering the effect of pounding between adjacent structures, and (iv) discusses the effect of earthquake characters on the selection of the optimum parameters of the system.

\section{Anticollision System}

The results of existing research studies without considering the effect of pounding between adjacent buildings show that optimum parameters of the anticollision system may be influenced by the stiffness ratio, mass ratio, period ratio, and separate distance between adjacent buildings. Number and location of the dampers may also have effect on the structural vibration control especially for the multistory buildings. All of these influences require a large number of statistical analysis; therefore, a simplified single-story structure connecting only one damper without considering the influence of structure characters is studied first in this paper (Figure 1), between the damper and the structure are hinge points. The method for selecting the optimum parameters of the anticollision system in aspect of horizontal excitation is proposed. The two reinforced concrete structures are both 4 meters in height and 6 meters in span, connected with a viscoelastic damper fixed on the steel plates which are reinforced on the beams ignoring the deformation. The viscoelastic damper consists of a single spring and dashpot in parallel, which is described by Kelvin model:

$$
f(x)=K \Delta x(t)+C \Delta \dot{x}(t),
$$

where $f$ is the damper force, $K$ is the stiffness coefficient of damper, and $C$ is the damping coefficient of damper, which means that the damper force is related to the displacement

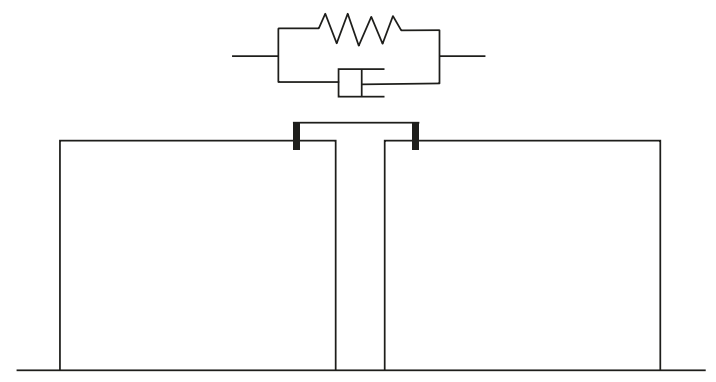

FIgURE 1: Simplified model of adjacent structures connected with joint damper.

and velocity difference. Hertz model, which is commonly used to model contact, is used in this model to consider the pounding stiffness only related to compression amount of the element ignoring the consumption of energy during the pounding.

The structures (hereinafter referred to as LT1 for left structure and RT2 for right structure) are set up as a separable reinforced concrete solid model in LS-DYNA, with the same structural stiffness of $2.3 \times 10^{6} \mathrm{~N} / \mathrm{m}$ and a period ratio of $1 / 2$. The reinforcement is simulated with $3 \mathrm{D}$ bar unit LINK160, and the concrete is simulated with 3D solid unit SOLID164. The damper is simulated by two springs and damping unit COMBI165 based on the Kelvin model. The mass of both structures is distributed on the beam, which is more suitable for the pounding analysis [23]. The horizontal load is assumed to occur in only one direction so that the problem can be simplified as a two-dimensional problem. The contact between the adjacent structures is simulated by penalty function method in LS-DYNA with the contact stiffness of $2.1 \times 10^{6} \mathrm{kN} / \mathrm{m}$.

\section{Control Variables}

The optimum parameters of anticollision system are mainly influenced by three aspects: level of destruction in both structures, utilization of energy dissipation system, and total strain energy consumed by the two structures. There are quite a number of damage indices proposed to estimate the level of destruction in buildings, including the singleparameter indices such as interstory displacement ratio which is used in the current earthquake resistant code in China and multiparameter indices considering both deformation and accumulative energy consumption of buildings. However, the best damage index to describe the level of structural destruction is still controversial in spite of a large amount of comparative analysis [24]. Therefore, interstory displacement ratio (IDR), as the most frequently used index in practice by far, is selected to be one of the control variables. Besides, a new parameter is defined in this paper:

$$
\text { energy consumption ratio }(\mathrm{ECR})=\frac{\text { energy consumed by damper }}{\text { energy consumed by structures }+ \text { energy consumed by damper }}
$$


which means the damper will consume relatively more energy than structures if ECR is high so that the utilization of energy dissipation system will be improved correspondingly, which is a benefit to the structures. A higher ECR for the same ground motion also means a better utilization of energy dissipation system.

There are 3 principles for the selection of optimum parameters:

(1) IDR of the two structures should be no larger than the situation without pounding; if IDR could not meet the requirement, the level of destruction should be same with the nonpounding situation according to the damage index proposed by Gao and Shen [25]; if IDR could not meet both requirements above, the minimum IDR of the structures would be chosen

(2) ECR should be no less than $50 \%$

(3) The total energy consumed by the two structures (TE) should be decreased comparing with the nonpounding situation

The stiffness coefficient and damping coefficient of the damper with which the adjacent structures could follow all the principles above are considered to be the optimum parameters. All of the optimum parameters make up the range of optimum parameters. Therefore, there are 4 control variables discussed in this study, including IDR of structure LT1, IDR of structure RT2, TE, and ECR.

\section{Selecting Ground Motion Records}

Ground motion records are selected for the time-history analysis that refer to "General rule for performance-based seismic design of buildings" edited by Xie Lili, listed in Table 1. The ground motion GM11, GM41, and GM71 are original records with the peak ground acceleration (PGA) of $0.34 \mathrm{~g}, 0.30 \mathrm{~g}$, and $0.24 \mathrm{~g}$, respectively ( $\mathrm{g}$ is the acceleration due to gravity). PGA of ground motion GM1, GM2, and GM3 is scaled to $0.4 \mathrm{~g}, 0.2 \mathrm{~g}$, and $0.1 \mathrm{~g}$, respectively, and PGA of the rest records from different sites are all scaled to $0.2 \mathrm{~g}$. Besides, white noise as a frequently used record in the structural vibration control analysis is selected with amplitude of $0.2 \mathrm{~g}$ in this study. The scaling factors for ground motion are given in this table.

\section{Analysis Results}

5.1. Procedure for Selecting Optimum Parameters. There are two parameters for the anticollision system studied in this paper, including the stiffness coefficient $K$ and damping coefficient $C$. Ground motion GM1 is input to discuss the relationship between the two parameters. Effects of $C$ and $K$ on IDR, TE, ECR, and the range of optimum parameters are shown in Figure 2.

It is seen that when $K$ is $0 \mathrm{~N} / \mathrm{m}$ or $10^{5} \mathrm{~N} / \mathrm{m}$, the values of all control variables are almost the same whatever $C$ is. IDR of the structure LT1 is significantly reduced with $C$ between $3 \times 10^{5} \mathrm{Ns} / \mathrm{m}$ and $10^{6} \mathrm{Ns} / \mathrm{m}$ when $K$ is $10^{6} \mathrm{~N} / \mathrm{m}$, while other control variables are also close to the value when $K$ is $0 \mathrm{~N} / \mathrm{m}$
TABLE 1: Ground motion records for time-history analysis.

\begin{tabular}{lccccc}
\hline No. & Earthquake & PGA & Site & $\begin{array}{c}\text { Scaling } \\
\text { factor }\end{array}$ & $\begin{array}{c}\text { PGA after } \\
\text { scaled }\end{array}$ \\
\hline GM11 & 1940, El Centro & $0.34 \mathrm{~g}$ & IIIII & 1 & $0.34 \mathrm{~g}$ \\
GM41 & 1994, Northridge & $0.30 \mathrm{~g}$ & II & 1 & $0.30 \mathrm{~g}$ \\
GM71 & 1980, Mammoth Lakes & $0.24 \mathrm{~g}$ & I & 1 & $0.24 \mathrm{~g}$ \\
GM1 & 1940, El Centro & $0.34 \mathrm{~g}$ & IIIII & 1.17 & $0.4 \mathrm{~g}$ \\
GM2 & 1940, El Centro & $0.34 \mathrm{~g}$ & IIIII & 0.59 & $0.2 \mathrm{~g}$ \\
GM3 & 1940, El Centro & $0.34 \mathrm{~g}$ & IIIII & 0.29 & $0.1 \mathrm{~g}$ \\
GM4 & 1994, Northridge & $0.30 \mathrm{~g}$ & II & 0.66 & $0.2 \mathrm{~g}$ \\
GM5 & 1992, Landers-June & $0.13 \mathrm{~g}$ & II & 1.55 & $0.2 \mathrm{~g}$ \\
GM6 & 1981, Westmoreland & $0.36 \mathrm{~g}$ & IV & 0.55 & $0.2 \mathrm{~g}$ \\
GM7 & 1980, Mammoth Lakes & $0.24 \mathrm{~g}$ & I & 0.83 & $0.2 \mathrm{~g}$ \\
Noise & White noise & $0.2 \mathrm{~g}$ & - & 1 & $0.2 \mathrm{~g}$ \\
\hline
\end{tabular}

or $10^{5} \mathrm{~N} / \mathrm{m}$. It is also seen that when $K$ is $10^{7} \mathrm{~N} / \mathrm{m}$, the structure cannot be controlled very well in all aspects due to the overlarge stiffness between the two structures which makes them nearly rigidly connected. The ranges of optimum damping coefficient $C$ for different stiffness coefficient $K$ are listed in Table 2. The results show that the ranges of optimum damping coefficient are same with the value from $3 \times 10^{5} \mathrm{Ns} / \mathrm{m}$ to $10^{6} \mathrm{Ns} / \mathrm{m}$ when $K$ is $10^{5} \mathrm{~N} / \mathrm{m}$ and $10^{6} \mathrm{~N} / \mathrm{m}$, but the range is a little larger if $K$ is $0 \mathrm{~N} / \mathrm{m}$ with the value from $2 \times 10^{5} \mathrm{Ns} / \mathrm{m}$ to $1.25 \times 10^{6} \mathrm{Ns} / \mathrm{m}$. Therefore, it could be considered that the value of stiffness coefficient $K$ have little effect on the range of optimum damping coefficient $C$ within a certain range of $K$.

Effects of $K$ on control variables are also shown in Figure 2. If the damping coefficient $C$ is $5 \times 10^{5} \mathrm{Ns} / \mathrm{m}$, it has significant effect on all control variables when $K$ is less than $10^{7} \mathrm{~N} / \mathrm{m}$ but little effect on them when $K$ has a value above $10^{7} \mathrm{~N} / \mathrm{m}$. However, if $C$ is $0 \mathrm{Ns} / \mathrm{m}$, the damper does not have the ability to consume the energy and also has little effect on the structural control, with which will increase the energy consumed by structures (TE). For this reason, the situation that $C=0 \mathrm{Ns} / \mathrm{m}$ will not be considered. Besides, when $C$ is $5 \times 10^{5} \mathrm{Ns} / \mathrm{m}$ and $K$ is less than $10^{5} \mathrm{~N} / \mathrm{m}$, the damper has almost the same effect on the control variables, which is in accordance with the results above. When $C$ is $5 \times 10^{5} \mathrm{Ns} / \mathrm{m}$ and $K$ is more than $10^{5} \mathrm{~N} / \mathrm{m}$, as the stiffness coefficient $K$ increases, IDR of structure LT1 first decreases and then increases, while IDR of structure RT2 increases first and then decreases a little. IDR of the two structures tends to be the same value when $K$ is large enough. In particular, IDR of the stiffer structure LT1 is reduced significantly as the stiffness coefficient $K$ increases from $10^{5} \mathrm{~N} / \mathrm{m}$ to $10^{6} \mathrm{Ns} / \mathrm{m}$, while TE and ECR are turning to the negative trend which is so little that could be neglected. As the stiffness coefficient $K$ increases above $10^{6} \mathrm{~N} / \mathrm{m}$, ECR decreased rapidly until 0 , and TE increases dramatically. It can be seen that the two structures are nearly rigidly connected and moving together when the stiffness coefficient $K$ is large enough. In this case, pounding is avoided between two structures, but TE of the adjacent structures has a great increase. Therefore, the most efficient method to reduce the damage is to achieve balance among all control variables rather than rigid connection between adjacent buildings to avoid pounding. The optimum 

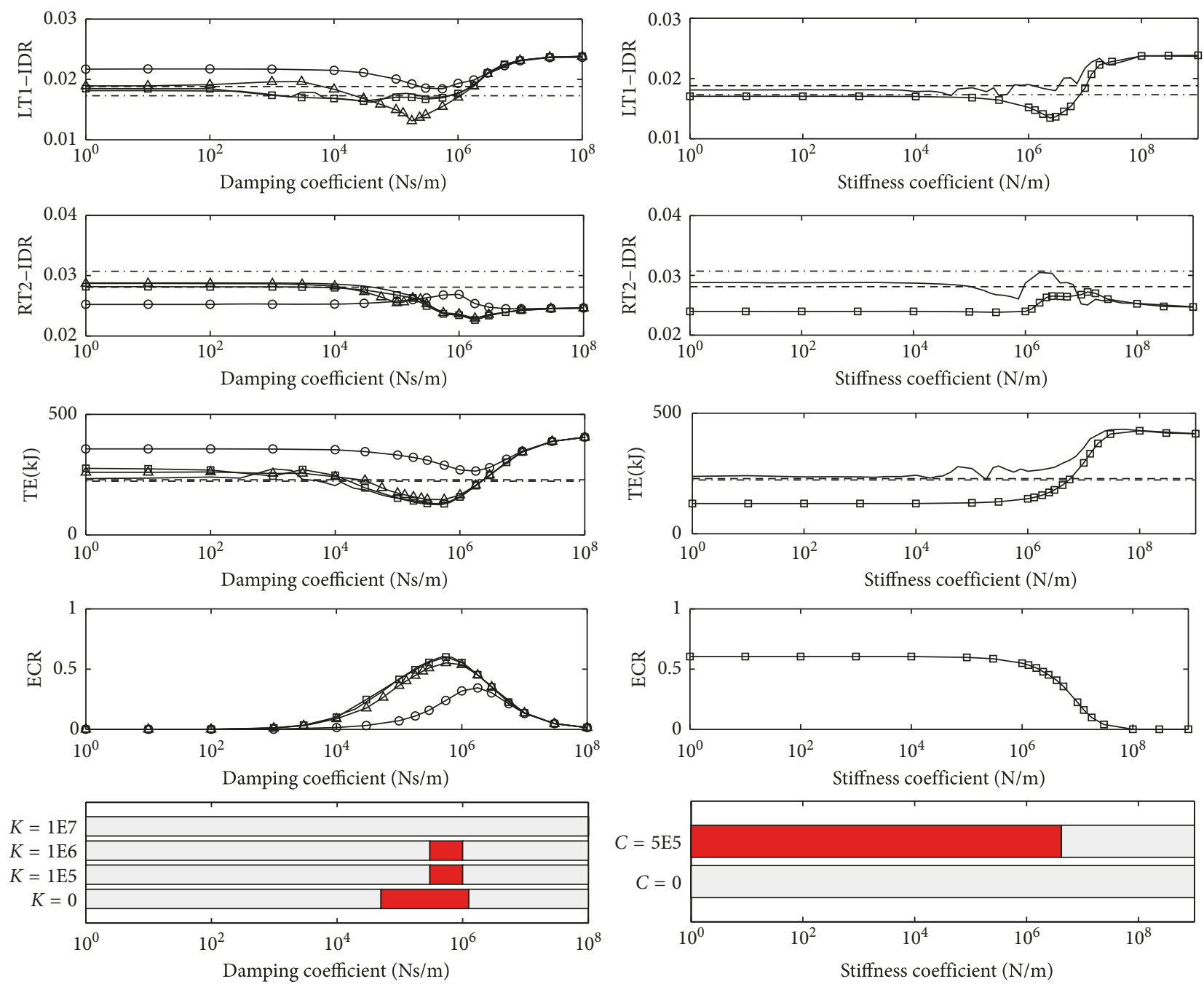

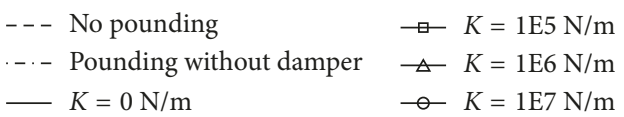

- - No pounding $\quad-C=0 \mathrm{Ns} / \mathrm{m}$

-. Pounding without damper $\rightarrow C=5 \mathrm{E} 5 \mathrm{Ns} / \mathrm{m}$

Figure 2: Effects of $C$ and $K$ on control variables and the range of optimum parameters.

Table 2: Range of optimum damping coefficient $C$ under earthquake GM1.

\begin{tabular}{lc}
\hline Stiffness coefficient $K\left(\mathrm{~N} \cdot \mathrm{m}^{-1}\right)$ & Damping coefficient $C\left(\mathrm{Ns} \cdot \mathrm{m}^{-1}\right)$ \\
\hline 0 & $2 \times 10^{5} \sim 1.25 \times 10^{6}$ \\
$10^{5}$ & $3 \times 10^{5} \sim 10^{6}$ \\
$10^{6}$ & $3 \times 10^{5} \sim 10^{6}$ \\
$10^{7}$ & -
\end{tabular}

damping coefficient $C$ is listed in Table 3 . When $C$ is $5 \times 10^{5} \mathrm{Ns} / \mathrm{m}$, the optimum stiffness coefficient $K$ should be less than $1.8 \times 10^{6} \mathrm{~N} / \mathrm{m}$ according to the selecting principles mentioned before. In addition, the structures would be controlled better if the stiffness coefficient is relatively larger in the range of optimum value.

As the value of stiffness coefficient $K$ has little effect on optimum damping coefficient $C$, the optimum parameters could be selected by following procedure, as shown in Figure 3:
(1) Selecting any stiffness coefficient $K_{0}$ to analyze $C_{1}$, range of optimum $C$

(2) Selecting damping coefficient $C_{0} \in C_{1}$ to analyze $K_{1}$, range of optimum $K$

(3) If $K_{0} \in K_{1}$ is true, $K_{1}$ and $C_{1}$ are the range of optimum stiffness coefficient and damping coefficient, respectively. If not, repeat (1) (3) until it is true.

5.2. Effect of Pounding on the Optimum Parameters. There are two main anticollision methods under study presently, including the impact absorbing materials filled in the gap and anticollision dampers connecting the adjacent buildings. People always neglect the collision after connecting the dampers between adjacent buildings in recent studies. In fact, pounding will still possibly occur between adjacent buildings if the distance is not enough between them, so it is important to discuss whether the pounding has effect on the optimum parameters of the anticollision system. Adjacent 
TABLe 3: $C=5 \times 10^{5} \mathrm{Ns} / \mathrm{m}$, range of optimum $K$ under earthquake GM1.

\begin{tabular}{|c|c|c|}
\hline Control variable & $\begin{array}{l}\text { Range of optimum } K \text { for each control variable } \\
\qquad\left(\mathrm{N} \cdot \mathrm{m}^{-1}\right)\end{array}$ & Range of optimum $K\left(\mathrm{~N} \cdot \mathrm{m}^{-1}\right)$ \\
\hline IDR & $0 \sim 10^{7}$ & \\
\hline ECR & $0 \sim 1.8 \times 10^{6}$ & $0 \sim 1.8 \times 10^{6}$ \\
\hline $\mathrm{TE}$ & $0 \sim 5.6 \times 10^{6}$ & \\
\hline
\end{tabular}

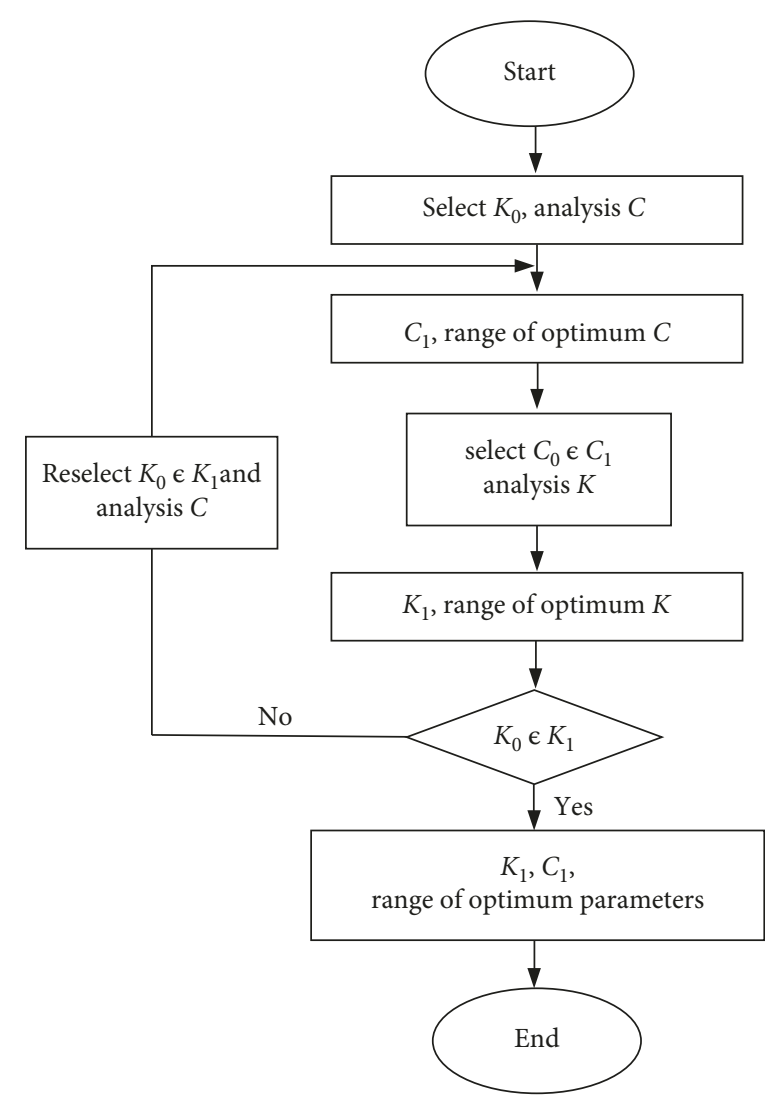

FIGURE 3: Procedure for selecting optimum parameters of anticollision system.

structures with a distance of $10 \mathrm{~mm}$ are studied in this study and ground motion GM11, GM41, and GM71 are selected for the time-history analysis.

Results of the optimum parameters considering pounding and without considering pounding are listed in Table 4 . The results from three ground motions consistently show that pounding would reduce the range of both optimum parameters. Results from ground motion GM11 are shown in Figure 4. As shown, the pounding count is not 0 in the ranges of both optimum parameters, which clearly shows that pounding still happens between adjacent structures connecting the energy dissipation system. The resultant curves of structures considering pounding are obviously different from that without considering pounding, which induces the range of optimum parameters narrower in the case of considering pounding. Therefore, analyzing the ranges of optimum parameters should consider the pounding between two buildings especially when the distance between two buildings is little.

\subsection{Effects of Earthquake Characters on Optimum Parameters}

5.3.1. PGA. PGA of ground motion El Centro (1940) is scaled to $0.4 \mathrm{~g}, 0.2 \mathrm{~g}$, and $0.1 \mathrm{~g}$, referred to as GM1, GM2, and GM3, respectively. The ranges of optimum parameters and pounding frequency (pounding count during one earthquake) are shown in Figure 5 and Table 5. The range of optimum damping coefficient $C$ is $3 \times 10^{5} \mathrm{Ns} / \mathrm{m} \sim 10^{6} \mathrm{Ns} / \mathrm{m}$ when $K$ is $10^{6} \mathrm{~N} / \mathrm{m}$, and then selecting the optimum damping coefficient $C=5 \times 10^{5} \mathrm{Ns} / \mathrm{m}$ from the optimum range, the range of optimum stiffness coefficient $K$ which is less than $1.8 \times 10^{6} \mathrm{~N} / \mathrm{m}$ is obtained. PGA has effect on the ranges of optimum parameters, and as shown in the pictures, the adjacent buildings could not avoid pounding if PGA is large, which would be the main reason for the change of optimum ranges.

5.3.2. Frequency and Duration. The ground motion GM2 and GM4 GM7 which are from different sites with PGA all 
TABLE 4: Comparison between the structures considering pounding and without considering pounding.

\begin{tabular}{|c|c|c|c|c|c|c|}
\hline \multirow{2}{*}{ Range of optimum parameters } & \multicolumn{2}{|c|}{ GM11 } & \multicolumn{2}{|c|}{ GM41 } & \multicolumn{2}{|c|}{ GM71 } \\
\hline & $C\left(\mathrm{Ns} \cdot \mathrm{m}^{-1}\right)$ & $K\left(\mathrm{~N} \cdot \mathrm{m}^{-1}\right)$ & $C\left(\mathrm{Ns} \cdot \mathrm{m}^{-1}\right)$ & $K\left(\mathrm{~N} \cdot \mathrm{m}^{-1}\right)$ & $C\left(\mathrm{Ns} \cdot \mathrm{m}^{-1}\right)$ & $K\left(\mathrm{~N} \cdot \mathrm{m}^{-1}\right)$ \\
\hline $\begin{array}{l}\text { Without considering pounding } \\
\text { Considering pounding }\end{array}$ & $\begin{array}{c}1.8 \times 10^{5} \sim 10^{6} \\
3 \times 10^{5} \sim 10^{6}\end{array}$ & $\begin{array}{c}0 \sim 3 \times 10^{6} \\
0 \sim 1.8 \times 10^{6}\end{array}$ & $\begin{array}{l}3 \times 10^{4} \sim 5.6 \times 10^{6} \\
3 \times 10^{5} \sim 5.6 \times 10^{6}\end{array}$ & $\begin{array}{l}0 \sim 1.7 \times 10^{7} \\
0 \sim 10^{7}\end{array}$ & $\begin{array}{c}1 \times 10^{5} \sim 3 \times 10^{6} \\
1.8 \times 10^{5} \sim 3 \times 10^{6}\end{array}$ & $\begin{array}{c}0 \sim 3 \times 10^{6} \\
0 \sim 1.8 \times 10^{6}\end{array}$ \\
\hline
\end{tabular}
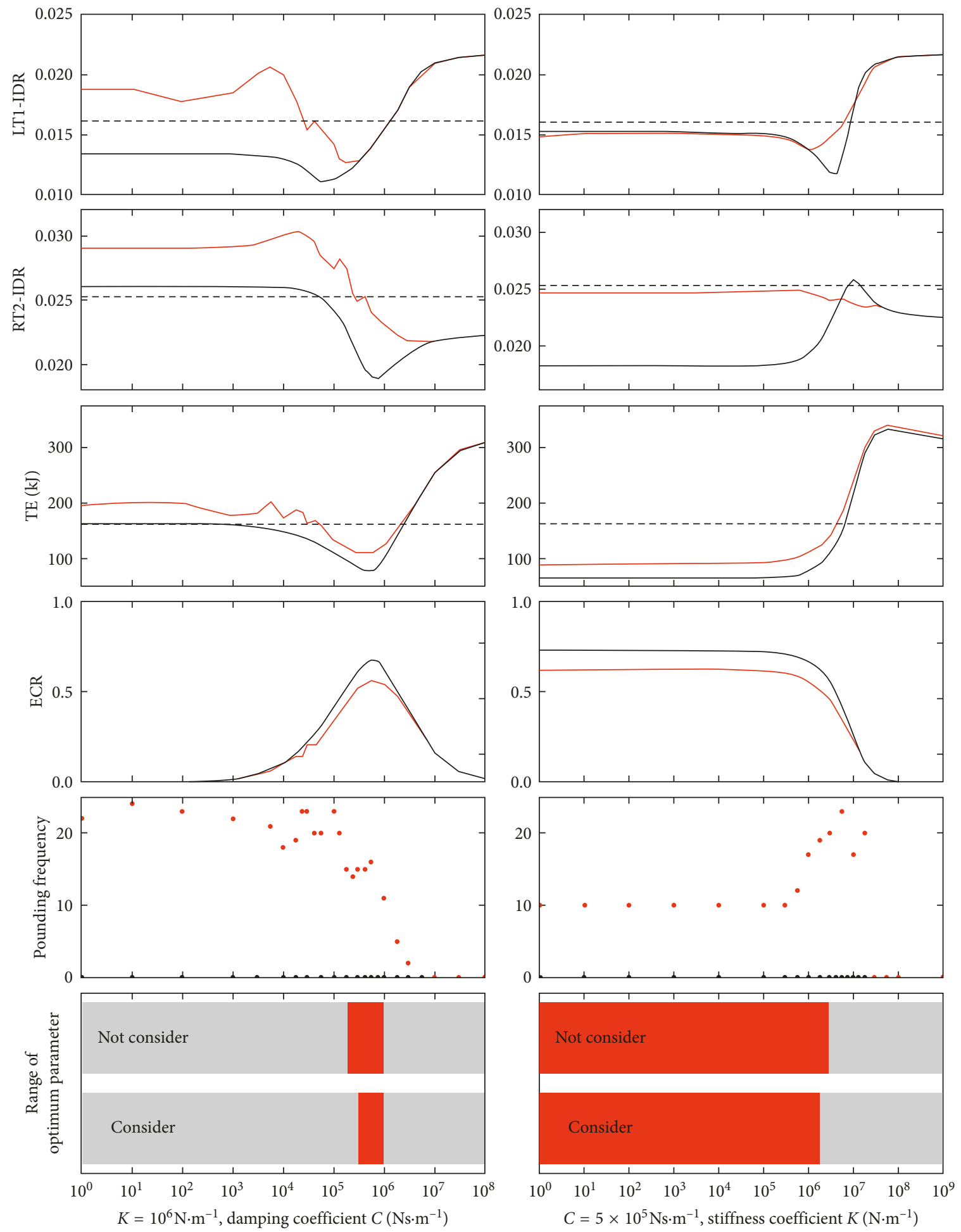

_ Considering pounding

_ Without considering pounding

- - - No pounding

FIGURE 4: Comparison between the structures considering pounding and without considering pounding (GM11). 

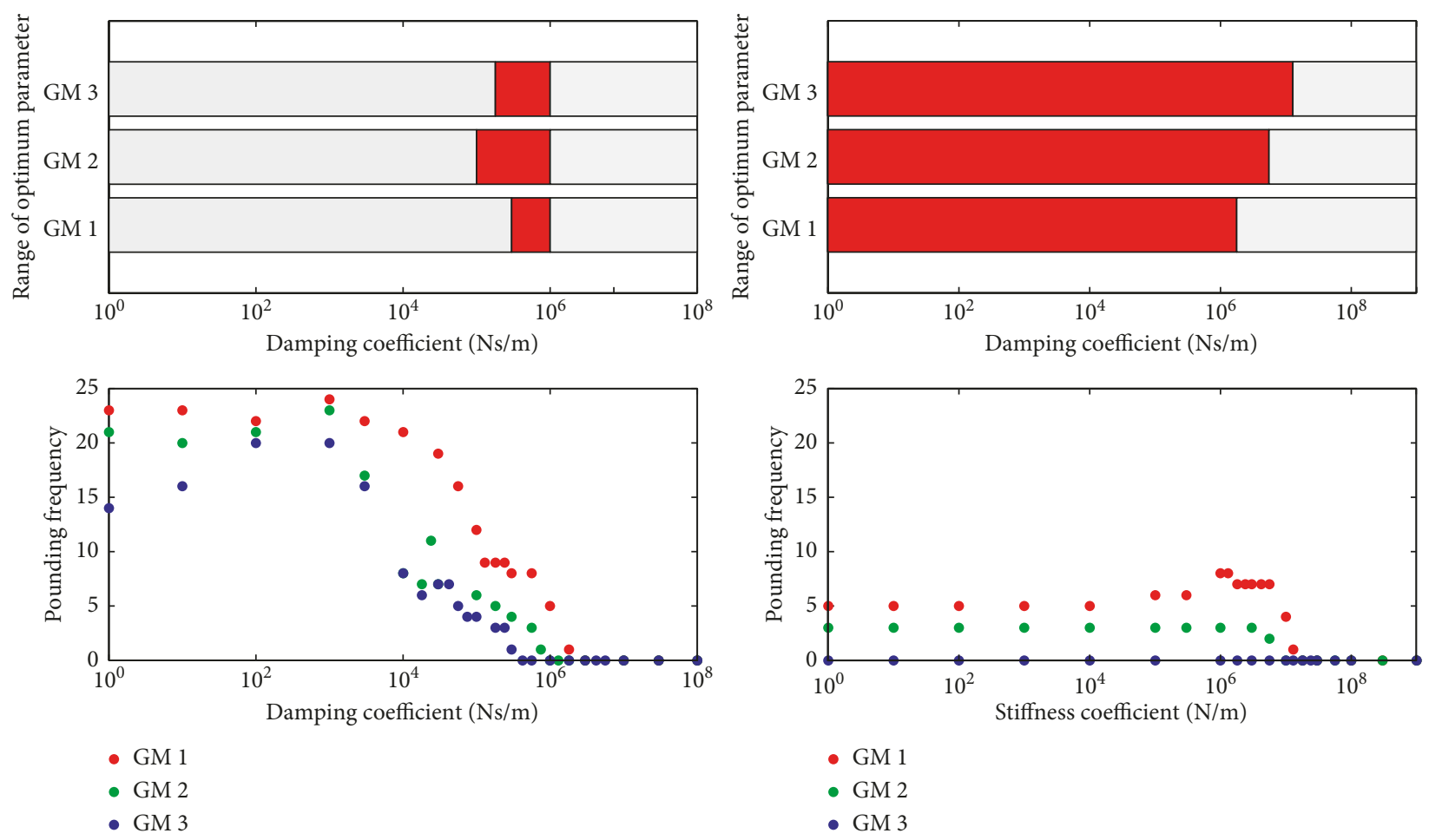

FIGURE 5: Ranges of optimum parameters and pounding frequency (GM1, GM2, and GM3).

TABLE 5: Ranges of optimum parameters under earthquakes with different PGA.

\begin{tabular}{lcc}
\hline Earthquake & $\begin{array}{c}\text { Damping coefficient } \\
C\left(\mathrm{Ns} \cdot \mathrm{m}^{-1}\right)\end{array}$ & Stiffness coefficient $K\left(\mathrm{~N} \cdot \mathrm{m}^{-1}\right)$ \\
\hline GM1 & $3 \times 10^{5} \sim 10^{6}$ & $0 \sim 1.8 \times 10^{6}$ \\
GM2 & $10^{5} \sim 10^{6}$ & $0 \sim 5.6 \times 10^{6}$ \\
GM3 & $1.8 \times 10^{5} \sim 10^{6}$ & $0 \sim 1.3 \times 10^{7}$ \\
\hline
\end{tabular}

scaled to $0.2 \mathrm{~g}$ are input to the structures to analyze the optimum parameters of the anticollision system. Results are shown in Figure 6 and Table 6. It is seen that the ranges of optimum parameters have significant difference from different earthquakes, especially for the results from ground motion GM5 and GM6 which is much narrower than others, but there are also overlaps. Hence, the frequency and duration of earthquakes have effect on the optimum parameters.

Besides, the results show that pounding could not be avoided under some earthquakes, and the results from white noise, which is the most frequently used record in the study of structural vibration control, also have some differences from the results obtained by earthquakes. In particular, the resultant curves of ECR and TE with stiffness coefficient $K$ obtained by white noise even change in an opposite trend when $K$ is in the range from $10^{6} \mathrm{~N} / \mathrm{m}$ to $10^{8} \mathrm{~N} / \mathrm{m}$ compared with those results obtained by earthquakes, which would finally influence the selection of optimum parameters, as shown in Figure 7. It means that the results from white noise are not representative enough, so inputting more earthquake records to consider the effect of earthquake characters for the analysis instead of a single white noise is quite necessary.

In conclusion, earthquake characters such as PGA, frequency, and duration have the effect on the ranges of optimum parameters of the anticollision system. Even if the adjacent buildings are connecting damper with the optimum parameters, pounding would still occur between the two buildings under some earthquakes, which may be one of the most important factors to influence the ranges of optimum parameters. White noise has a uniform frequency distribution, and it induces little displacement response which is totally different from the earthquakes. The results obtained by inputing white noise cannot represent the results from earthquake record. However, the ranges of optimum parameters have overlaps even though they are different under different earthquakes. Therefore, the accurate ranges of optimum parameters can be received by inputting multiple earthquake records for the time-history analysis considering the intensity of earthquake resistance of the buildings and site condition.

5.4. Discussions. Time-history results of displacements and pounding force under ground motion GM2 are shown in Figure 8 as an example. The maximum displacement of structure LT1 without pounding under GM2 is $0.042 \mathrm{~m}$, and the maximum IDR is 0.010 that belongs to heavy damage [24]. In fact, pounding will still occur when the distance between them is $25 \mathrm{~mm}$, and IDR of structure LT1 will increase to 0.018 that will induce the structure collapse directly. If the anticollision system with stiffness coefficient 

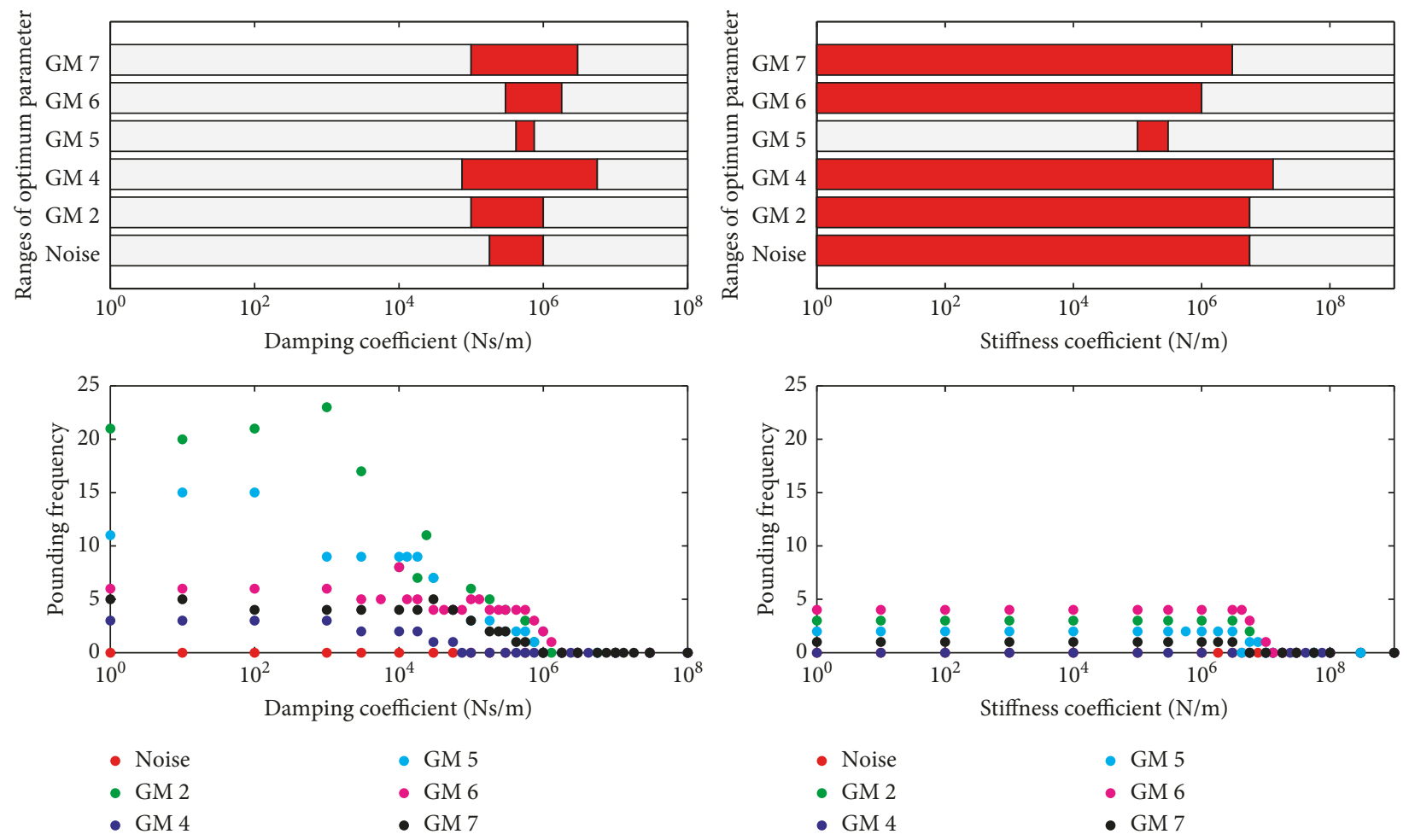

FIGURE 6: Ranges of optimum parameters and pounding frequency under different ground motions.

TABLE 6: PGA $=0.2 \mathrm{~g}$, ranges of optimum parameters under different ground motions.

\begin{tabular}{lcr}
\hline Earthquake & Damping coefficient $C\left(\mathrm{Ns} \cdot \mathrm{m}^{-1}\right)$ & ${\text { Stiffness coefficient } K\left(\mathrm{~N} \cdot \mathrm{m}^{-1}\right)}^{-1.8 \times 10^{5} \sim 10^{6}}$ \\
\hline Noise & $10^{5} \sim 10^{6}$ & $0 \sim 5.6 \times 10^{6}$ \\
GM2 & $7.5 \times 10^{4} \sim 5.6 \times 10^{6}$ & $0 \sim 5.6 \times 10^{6}$ \\
GM4 & $4.2 \times 10^{5} \sim 7.5 \times 10^{5}$ & $0 \sim 1.3 \times 10^{7}$ \\
GM5 & $3 \times 10^{5} \sim 1.8 \times 10^{6}$ & $10^{5} \sim 3 \times 10^{5}$ \\
GM6 & $10^{5} \sim 3 \times 10^{6}$ & $0 \sim 10^{6}$ \\
GM7 & & $0 \sim 3 \times 10^{6}$ \\
\hline
\end{tabular}

$K=10^{6} \mathrm{~N} / \mathrm{m}$ and damping coefficient $C=5 \times 10^{5} \mathrm{Ns} / \mathrm{m}$ is connected between the two structures, IDR of structure LT1 will be reduced to 0.0086 belonging to moderate damage, and the damper will consume $80.6 \%$ energy of the whole system including two structures and the damper. In addition, both the pounding count and pounding force will be reduced by connecting the damper. In this case, the anticollision system could be fully used, and the damage induced by pounding would be efficiently reduced even less than the situation without pounding.

\section{Conclusions}

The optimum parameters of the anticollision system between adjacent structures are discussed by time-history analysis from the aspects of both pounding effects and ground motion input in this paper. The following conclusions can be summarized:

(1) Pounding will still possibly occur between adjacent buildings during earthquake if the distance between them is insufficient, which will influence the ranges of optimum parameters of the anticollision system. Hence, the pounding between adjacent buildings should be considered in selecting optimum parameters.

(2) Earthquake characters such as PGA, frequency, and duration have effects on the ranges of optimum parameters, but there are overlaps of them. So, it is strongly recommended to input more than three ground motion records for the time-history analysis considering the intensity of earthquake resistance of the buildings and site condition to calculate the accurate ranges of the optimum parameters.

Connecting the anticollision system between adjacent buildings can efficiently reduce the damage induced by pounding even if the two buildings still contact each other during the earthquake. Besides, for the case of little distance between adjacent buildings with the possibility of pounding, the effects of structural characters such as the mass ratio, stiffness ratio and damping ratio on the optimum parameters are still under study. 

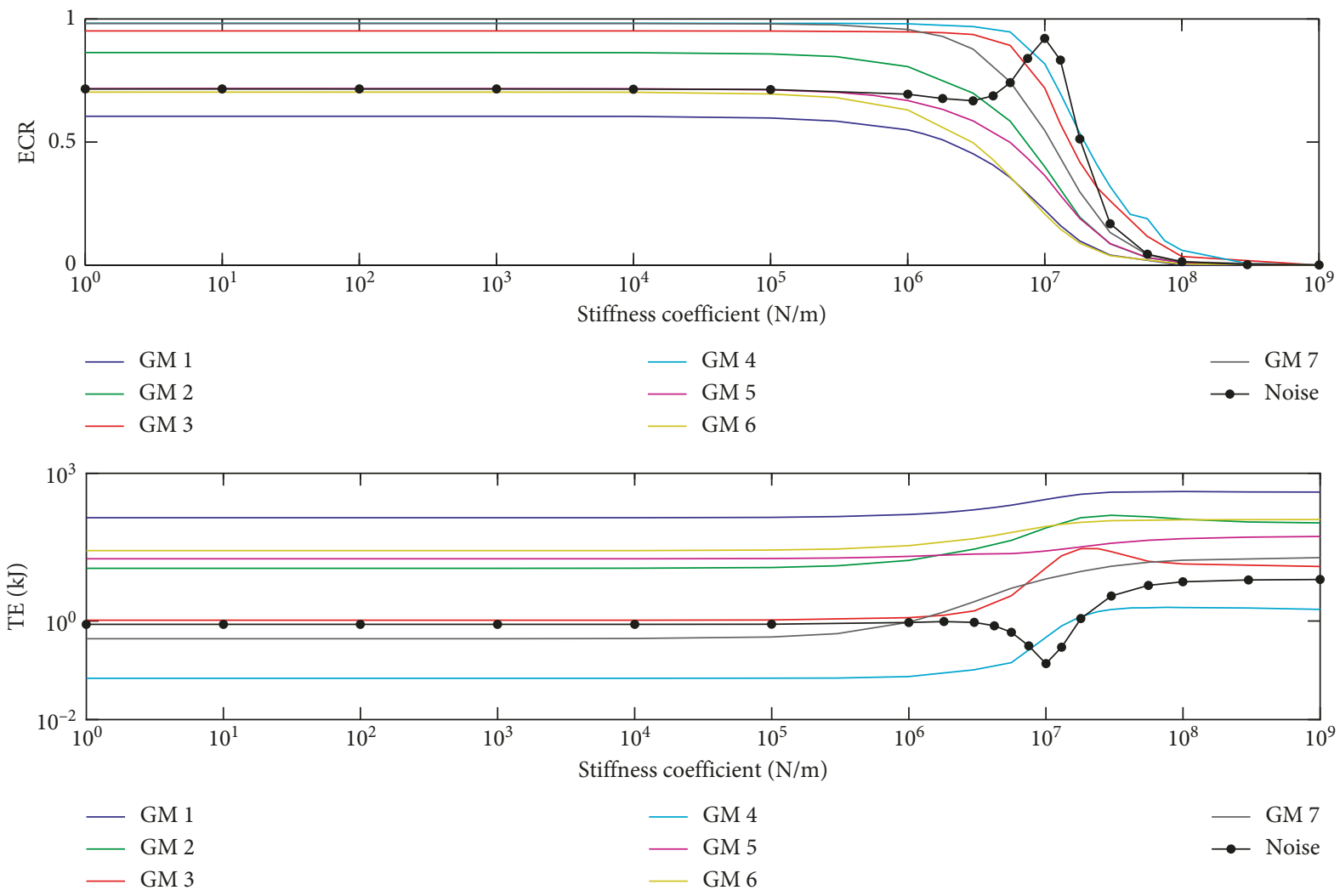

Figure 7: Relationships between ECR, TE, and stiffness coefficient $K$.
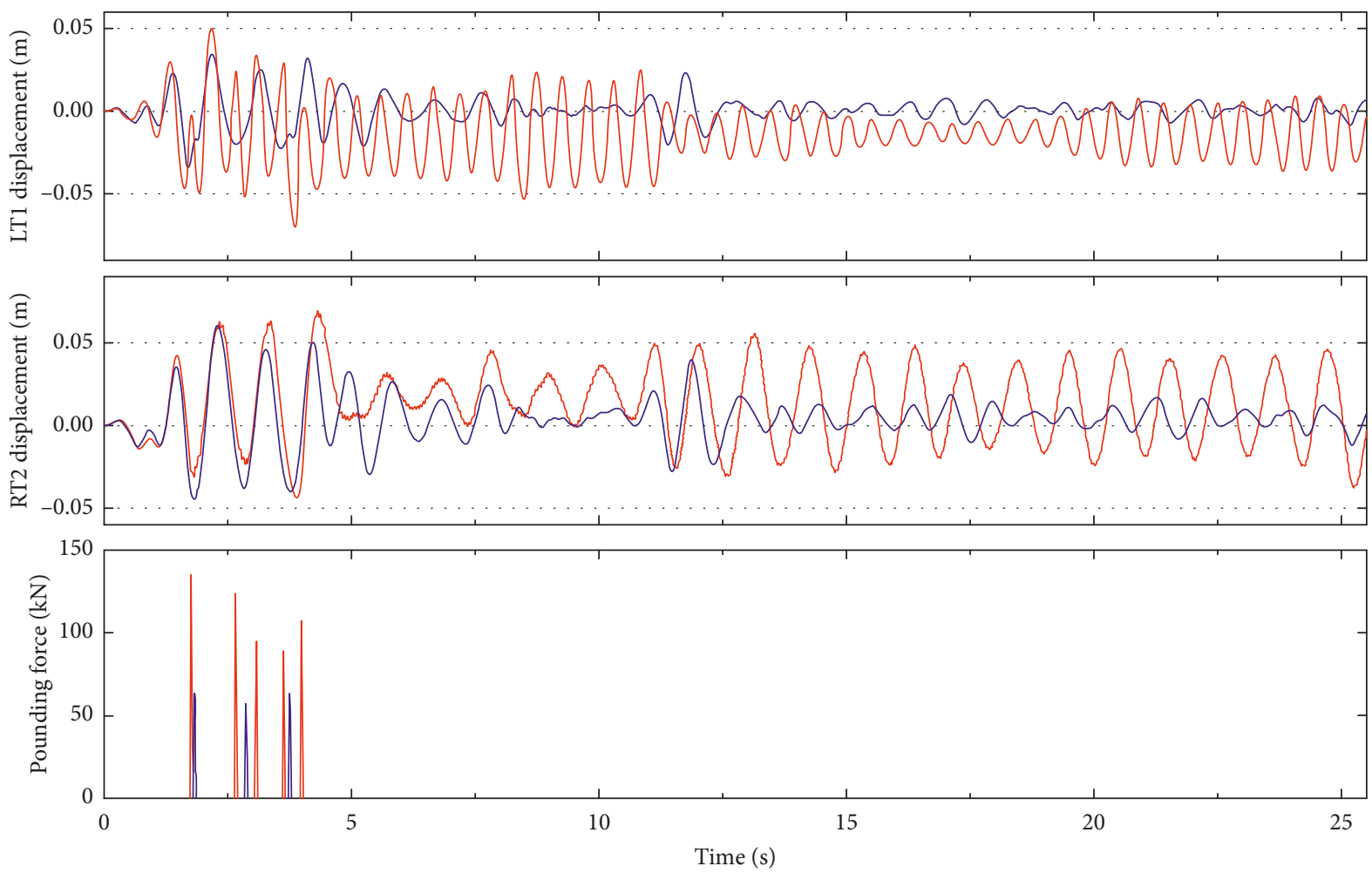

- Pounding

Connecting damper

Figure 8: Time-history curves of displacements and pounding forces under ground motion GM2. 


\section{Data Availability}

The data used to support the findings of this study are included within the article.

\section{Conflicts of Interest}

The authors declare that they have no conflicts of interest.

\section{Acknowledgments}

The authors appreciate the financial support from National Key R\&D Program of China (2017YFC1500602), National Natural Science Foundation of China (51308516), and Program for Innovative Research Team, China Earthquake Administration.

\section{References}

[1] Y. Q. Yang, Research on Seismic Pounding between Adjacent Buildings, Institute of Engineering Mechanics, Harbin, China, 2013.

[2] S. A. Anagnostopoulos and K. V. Spiliopoulos, "An investigation of earthquake induced pounding between adjacent buildings," Earthquake Engineering and Structural Dynamics, vol. 21, no. 4, pp. 289-302, 1992.

[3] H. D. Zou and Z. J. Lan, "Discussion on structural collision between adjacent buildings," Industrial Construction, vol. 4, p. 015, 2002.

[4] S. A. Anagnostopoulos, "Building pounding re-examined: how serious a problem is it," in Proceedings of Eleventh World Conference on Earthquake Engineering, p. 2108, Pergamon, Elsevier Science, Oxford, UK, June 1996.

[5] V. Warnotte, D. Stoica, S. Majewski, and M. Voiculescu, "State of the art in the pounding mitigation techniques," Intersections/Intersecții, vol. 4, no. 3, 2007.

[6] R. K. Miller, "Steady vibroimpact at a seismic joint between adjacent structures," in Proceedings of 7th World Conference on Earthquake Engineering, pp. 8-13, September 1980.

[7] S. A. Anagnostopoulos, "Pounding of buildings in series during earthquakes," Earthquake Engineering and Structural dynamics, vol. 16, no. 3, pp. 443-456, 1988.

[8] P. C. Polycarpou and P. Komodromos, "Numerical investigation of potential mitigation measures for poundings of seismically isolated buildings," Earthquake and Structures, vol. 2, no. 1, pp. 1-24, 2011.

[9] P. C. Polycarpou, P. Komodromos, and A. C. Polycarpou, “A nonlinear impact model for simulating the use of rubber shock absorbers for mitigating the effects of structural pounding during earthquakes," Earthquake Engineering and Structural Dynamics, vol. 42, no. 1, pp. 81-100, 2013.

[10] S. E. Abdel Raheem, "Mitigation measures for seismic pounding effects on adjacent buildings responses," in Proceedings of 4th Conference of Computational Mechanics, Structural Dynamics and Earthquake Engineering, COMPDYN, Kos Island, Greece, June 2013.

[11] S. E. Abdel Raheem, "Mitigation measures for earthquake induced pounding effects on seismic performance of adjacent buildings," Bulletin of Earthquake Engineering, vol. 12, no. 4, pp. 1705-1724, 2014.

[12] A. V. Bhaskararao and R. S. Jangid, "Seismic response of adjacent buildings connected with friction dampers," Bulletin of Earthquake Engineering, vol. 4, no. 1, pp. 43-64, 2006.
[13] A. V. Bhaskararao and R. S. Jangid, "Optimum viscous damper for connecting adjacent SDOF structures for harmonic and stationary white-noise random excitations," Earthquake Engineering and Structural Dynamics, vol. 36, no. 4, pp. 563-571, 2007.

[14] K. Farzin, M. Benyamin, and Y. Mansoor, "Enhancing the seismic performance of adjacent pounding structures using viscous dampers," in Proceedings of 16th European Conference of Earthquake Engineering, Thessaloniki, Greece, June 2018.

[15] X. Huang and H. P. Zhu, "Optimum parameters of dampers interconnecting adjacent structures under earthquakes," Journal of Vibration and Shock, vol. 32, no. 16, pp. 117-122, 2013.

[16] Y. L. Xu, Q. He, and J. M. Ko, "Dynamic response of damperconnected adjacent buildings under earthquake excitation," Engineering Structures, vol. 21, no. 2, pp. 135-148, 1999.

[17] W. S. Zhang and Y. L. Xu, "Dynamic characteristics and seismic response of adjacent buildings linked by discrete dampers," Earthquake Engineering and Structural Dynamics, vol. 28, no. 10, pp. 1163-1185, 1999.

[18] W. S. Zhang and Y. L. Xu, "Vibration analysis of two buildings linked by Maxwell model-defined fluid dampers," Journal of Sound and Vibration, vol. 233, no. 5, pp. 775-796, 2000.

[19] H. Zhu, Y. Wen, and H. Iemura, "A study on interaction control for seismic response of parallel structures," Computers and Structures, vol. 79, no. 2, pp. 231-242, 2001.

[20] H. P. Zhu and Y. L. Xu, "Optimum parameters of Maxwell model-defined dampers used to link adjacent structures," Journal of Sound and Vibration, vol. 279, no. 1-2, pp. 253-274, 2005.

[21] K. Bigdeli, W. Hare, and S. Tesfamariam, "Configuration optimization of dampers for adjacent buildings under seismic excitations," Engineering Optimization, vol. 44, no. 12, pp. 1491-1509, 2012.

[22] C. Vincent, P. Ioannis, and C. Thierry, "Shake table test of large scale structures subject to pounding," in Proceedings of 16th European Conference of Earthquake Engineering, Thessaloniki, Greece, June 2018.

[23] G. Cole, R. Dhakal, A. Carr, and D. Bull, "An investigation of the effects of mass distribution on pounding structures," Earthquake Engineering \& Structural Dynamics, vol. 40, no. 6, pp. 641-659, 2011.

[24] F. X. Zhao, Z. L. Ren, and Y. S. Zhang, "Uncertainty analysis of structural damage prediction based on different damage indices," Earthquake Research in China, vol. 24, no. 4, pp. 325-336, 2008.

[25] X. W. Gao and J. M. Shen, "Seismic reliability analysis of deformation capacity for RC frame structures under strong earthquakes," China Civil Engineering Journal, vol. 26, no. 3, pp. 3-12, 1993. 


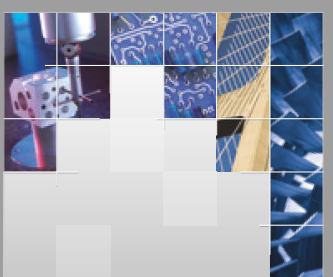

\section{Enfincering}
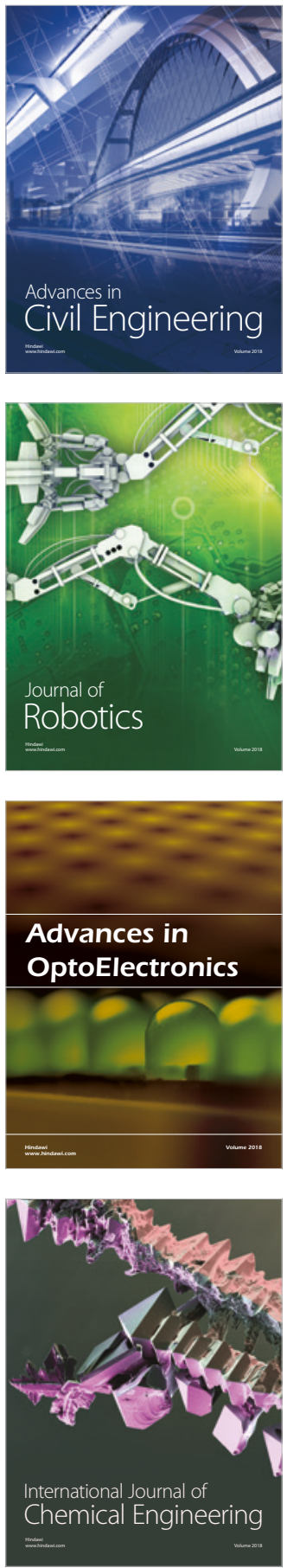

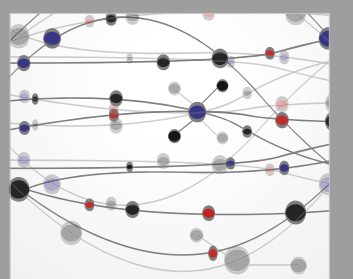

\section{Rotating \\ Machinery}

The Scientific World Journal

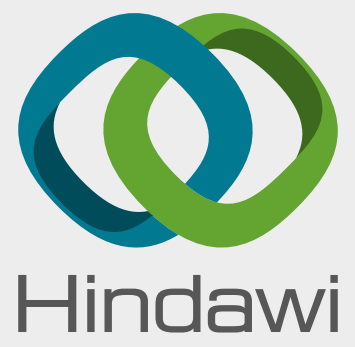

Submit your manuscripts at

www.hindawi.com
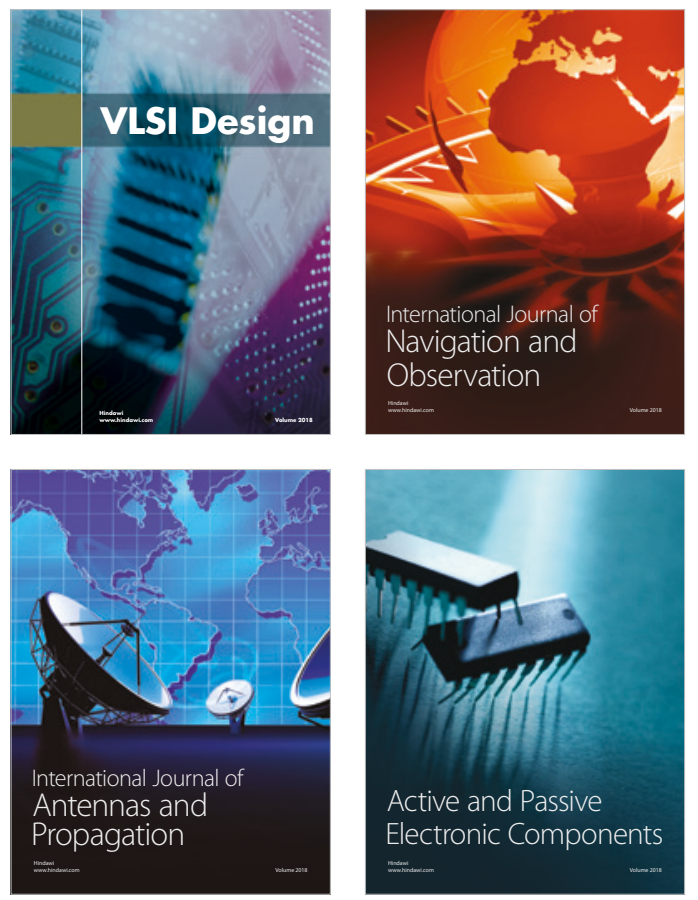
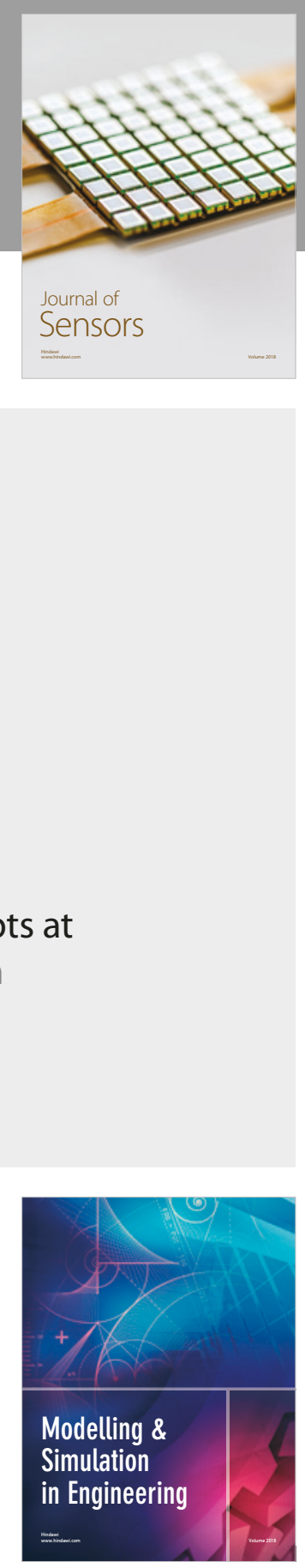

\section{Advances \\ Multimedia}
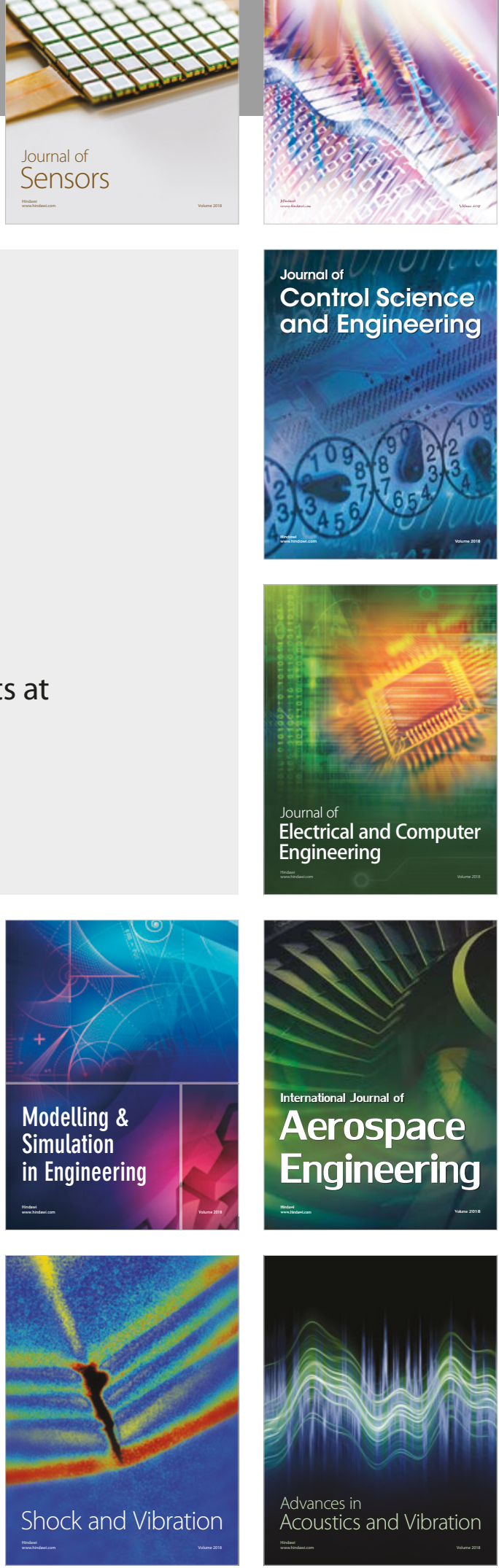